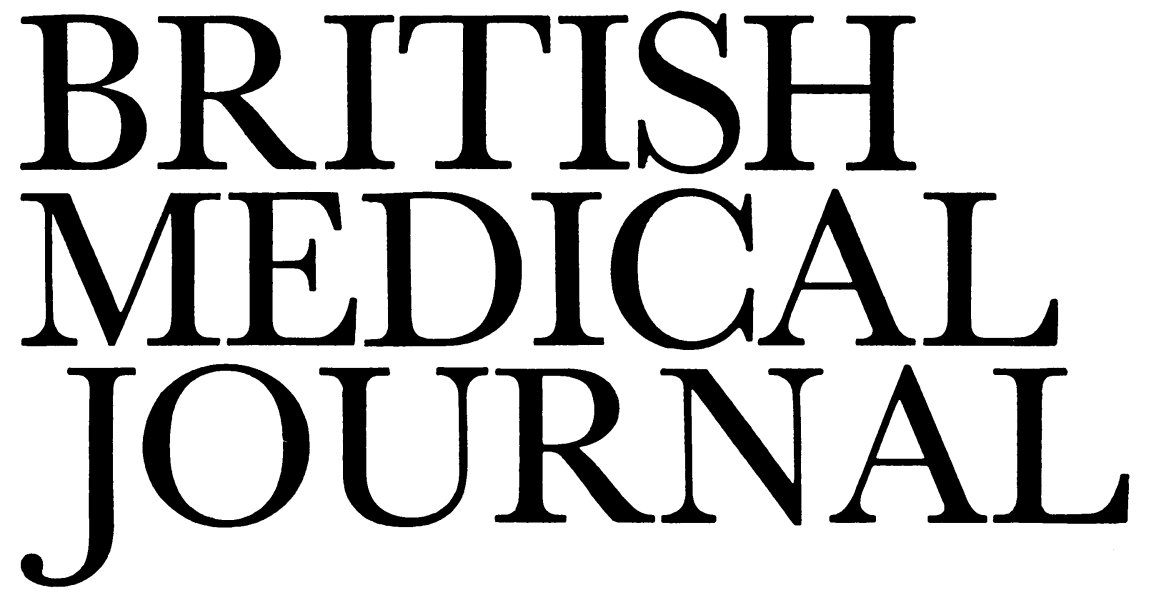

LONDON, SATURDAY 28 JUNE 1986

\title{
Halothane and the liver: the problem revisited and made obsolete
}

The problem of halothane and the liver does exist. Experience in Bristol of two bizarre cases of "halothane hepatitis" led Dr Brian Williams to organise a symposium on the subject earlier this year. His survey of anaesthetists in the South Western Region showed a high level (97\%) of awareness of the possibility of hepatitis associated with halothane. The reported incidence ranges from one in 10000 to one in 35000 anaesthetics in adults. The consensus seemed to be that repeated halothane anaesthesia was an important aetiological factor: of those who replied, three quarters let at least an arbitrary three months elapse before choosing to repeat the use of halothane, while two fifths required a minimum interval of six months.

The problem may be preventable. Dr Roger Williams described 48 patients ( 38 of whom died) who had been referred to the liver unit at King's College Hospital, London, from January 1965 to December $1983^{\prime}$; he gave details of a further eight patients admitted since then. Fewer patients might have been seen had note been taken of exposure to halothane within 26 days-and especially when the first anaesthetic had been followed by the non-specific sign of late onset fever. ${ }^{1}$ Other diagnoses such as non-A non-B hepatitis were impossible to exclude completely, but strong evidence that the patients had halothane hepatitis was provided by a relatively specific test based on sensitised rabbit hepatocytes; this was positive in 16 of 24 patients with liver failure associated with halothane. ${ }^{2}$

The pattern of the problem has also changed. ${ }^{3}$ Dr Williams referred to five cases among children, one of whom had died. It seems that the adult population may be divided into three groups: most may probably be given halothane with impunity -but that has to be a retrospective assessment. Up to one fifth respond on close repeated exposure to halothane with a mild rise in their transaminase activities and some prolongation of the prothrombin time. The remaining few develop jaundice, grossly raised activities of aspartate aminotransferase, encephalopathy in half, and rapidly progressive liver failure. No effective treatment has been found other than the hope of urgent liver transplantation.

Whether or not halothane hepatitis can be induced in animals is still not clear. Rats consistently develop a similar syndrome only when they are hypoxic, starved, male, and preferably pretreated with enzyme inducing drugs. In all these circumstances cimetidine reduces the hepatotoxicity of halothane by inhibiting the cytochrome P-450 oxidase system. ${ }^{4}$ Professor Michael Cousins from Adelaide showed that liver damage similar to that in man may be produced without hypoxia in guinea pigs. ${ }^{5}$ This work should dispel the erroneous (but growing) notion that halothane hepatitis results from negligent hypoxic anaesthesia.

What, then, is a safe interval between halothane anaesthetics? The question remains unanswered. Dr Kathleen Allsopp from the Medical Defence Union thought that it might become increasingly hard to find expert witnesses to defend the close repeated use of halothane and even its reuse after longer periods if minor non-specific signs of hepatitis had followed the first exposure. Ignorance of such an adverse response may not constitute an adequate defence, but no case has yet been tried in the British courts.

Anaesthetists should assume that any inadequately documented anaesthetic may have included halothane, and a family history of adverse responses to halothane should be sought since there is evidence now of genetic predisposition in humans. ${ }^{6}$

The problem is best solved by the alternatives to halothane. Total intravenous anaesthesia holds promise of a technique safe from pollution for patient and staff, but despite some advances an ideal agent is still not available. Abnormalities in liver function tests may follow methohexitone, ${ }^{7}$ thiopentone, ${ }^{8}$ and ketamine (or even-in one in 700 patients-precede anaesthesia $\left.{ }^{10}\right)$. Propofol has a low potential for altering liver function enzymes but it has only recently become available. ${ }^{11}$

Two recently introduced volatile agents, enflurane and isoflurane, are unlikely to result in toxic metabolites or breakdown products. Some $2 \%$ of absorbed enflurane and $0 \cdot 2 \%$ of isoflurane are metabolised, ${ }^{12}{ }^{13}$-compared with 15 $20 \%$ for halothane. Low blood gas solubilities, especially with isoflurane, ensure that these agents are rapidly expired from the body and so are unlikely to linger to form potentially toxic metabolites. Though enflurane is metabolised to inorganic fluoride ions, only subtle and reversible changes in renal function have been found, ${ }^{14}$ but caution may be necessary if other nephrotoxic agents are used concurrently. ${ }^{15}$

Hepatotoxicity after enflurane seems to be rare, and the 
suggestion $^{16}$ that it resembles halothane hepatitis has been denied. ${ }^{17}$ Liver problems have not been documented after isoflurane, but, none the less, four of 27 cases reported to a subcommittee of the Food and Drug Administration in the United States over four years could not be attributed to other factors.

The incidence of reports of hepatotoxicity related to enflurane or isoflurane has not increased in the United States despite these agents having almost supplanted halothane. If that experience is translated to Britain the incidence of liver failure due to enflurane is likely to be one case a year if all 3 million surgical patients given anaesthesia received enflurane. Early results from Oxford of comparative studies of enflurane or isoflurane in a population likely to develop hepatitis related to halothane show that neither agent results in any substantial changes in liver function values. ${ }^{18}$

What, then, should the anaesthetist do to protect his patient from the remote possibility of liver damage and himself from the threat of litigation? Are there now any absolute indications for the repeated use of halothane within six months? The only problem comes where inappropriate concern about the added cost of using enflurane or isoflurane (or failure to provide the means to deliver these agents) may force the anaesthetist to put the patient unnecessarily at risk. Surely it is reasonable for the added cost of more expensive agents to be borne by the health authorities rather than their having to join the medical insurers in paying potentially huge settlements for avoidable halothane hepatitis?

Halothane hepatitis is as rare as mortality related to anaesthesia itself, and it is avoidable given adequate equipment, records, and forethought. The revolution that resulted from the introduction of halothane is likely to be replaced by another-the use of the more expensive but less hazardous enflurane and isoflurane.

Colin E BlogG

Consultant Anaesthetist,

Nuffield Department of Anaesthetics,

Radcliffe Infirmary,

Oxford OX2 6HE

1 Neuberger J, Williams R. Halothane anaesthesia and liver damage. Br Med f 1984;289:1136-9.

2 Kenna JG, Neuberger J, Williams R. Enzyme-linked immunosorbent assay for detection of antibodies against halothane-altered hepatocyte antigens. F Immunol Methods 1984:75:3-14

Whitburn RH, Sumner E. Halothane hepatitis in an eleven-month child. Anaesthesia 1986; (in press)

4 Plummer JL, Wanwimolruk S, Jenner MA, Hall P de la M, Cousins MJ. Effects of cimetidine and ranitidine on halothane metabolism and hepatotoxicity in an animal model. Drug Metab Dispos 1984;12:106-10.

5 Lunam CA, Cousins MJ, Hall P de la $M$. Guinea-pig model of halothane-associated hepatotoxicity in the absence of enzyme induction and hypoxia. $\mathcal{F}$ Pharmacol $E x p$ Ther 1985;232:802-9.

6 Hoft RH, Bunker JP, Goodman HI, Gregory PB. Halothane hepatitis in three pairs of closely related women. $N$ Engl I Med 1981;304:1023-4.

7 Bittrich NM, Kane AV'R, Mosher RE. Methohexital and its effect on liver function tests. A comparative study. Anesthesiology 1963;24:81-90.

8 Dundee JW. Thiopentone as a factor in the production of liver dysfunction. $\mathrm{Br} \mathrm{f}$ Anaesth 1955;27:14-23.

9 Dundee JW, Fee JPH, Moore J, Mcllroy PDA, Wilson DB. Changes in serum enzyme levels following ketamine infusions. Anaesthesia 1980;35:12-6.

10 Schemel WH. Unexpected hepatic dysfunction found by multiple laboratory screening. Current Researches in Anaesthesia and Analgesia 1976;55:810-2.

11 Sear JW, Prys-Roberts C, Dye A. Hepatic function after anaesthesia for major vascular reconstructive surgery. A comparison of four anaesthetic techniques. Br $\mathcal{F}$ Anaesth 1983;55: $603-9$

12 Chase RE, Holaday DA, Fiserova-Bergerova V, Saidman LJ, Mack FE. The biotransformation of Ethrane in man. Anesthesiology 1971;35:262-7

13 Holaday DA, Fiserova-Bergerova V, Latto IP, Zumbiel MA. Resistance of isoflurane to biotransformation in man. Anesthesiology 1975;43:325-32.

14 Mazze RI, Calverley RK, Smith NT. Inorganic fluoride nephrotoxicity: prolonged enflurane and halothane anesthesia in volunteers. Anesthesiology 1977;46:265-71.

15 Corrall IM, Snowdon S, Foëx P, et al. Enflurane in clinical practice. In: Bennetts FE, ed. Selected proceedings of the sixth European congress of anaesthesiology. New York: Biomedical Information Corporation, 1983:77.95.

16 Lewis JH, Zimmerman HJ, Ishak KG, et al. Enflurane hepatotoxicity. A clinicopathologic study of 24 cases. Ann Intern Med 1983;98:984-92.

17 Eger EI, Smuckler EA, Ferrell LD, et al. Is enflurane hepatotoxic? Anesth Analg 1986;65:21-30.

18 Trowell J, Peto R, Smith AC. Controlled trial of repeated halothane anaesthetics in patients with carcinoma of the uterine cervix treated with radium. Lancet 1975;i:821-4.

\section{Obese deceivers?}

Without doubt obese people owe their excess body weight to the consumption of food energy in excess of their expenditure, ' yet many studies of food intake by the obese have shown-paradoxically - that their energy intakes are not excessive. In addition, a multitude of largely anecdotal, but occasionally well documented, examples have been reported of individuals who maintain excessive weight despite caloric restriction. ${ }^{2}$ The paradox has led many workers to propose and seek for metabolic causes, either in lower basal metabolic rates or lower expenditure in activities. In recent years a biochemical basis has been postulated for this apparent metabolic efficiency, ${ }^{3}$ leading to considerable interest in thermogenesis induced by diet and to elegant studies of brown adipose tissue.

The study of energy balance with the precision needed to test these various hypotheses has to overcome two main difficulties: firstly, the measurement of energy expenditure in people leading a normal life, and, secondly, the measurement of food intake and its translation into nutrient intake, the major challenge to the quantitative study of human nutrition. ${ }^{4}$ The first of these problems seems to have been solved by using water double labelled with deuterium and oxygen-18 together with improved instruments for measuring isotope mass ratio. We now have a procedure for measuring energy expenditure in free living people that is both ethical and non-restrictive. ${ }^{5}$ The method provides a measure of carbon dioxide production, and thus provides data equivalent to those generated by well established indirect calorimetric procedures.

A recent study by Prentice and colleagues (12 April, p 983) attempted to tackle various elements of the energy balance paradox in a group of women who became obese during or after pregnancy and compared them with a group of lean women. Their conclusion was that in this type of obesity (and possibly other types of maturity onset obesity) the cause of the paradox lies in the underestimation of food intake by the individuals being studied. They found that the basal metabolic rates of the obese women were higher than those of the lean ones-in proportion to their lean body mass. Their 24 hour energy expenditures, measured by classic indirect calorimetry, were also higher, as were their energy expenditures in their normal life, as measured by the use of double labelled water. In both cases total energy expenditures were related to their increased body weight.

The recorded food intake of the obese people was, however, lower than that of the lean-and some $800 \mathrm{kcal}$ less than energy expenditure. The obese group had lost weight during the study but even when this was taken into account their intakes were less than their expenditures by at least 500 $\mathrm{kcal}$ a day. Since the authors could find no evidence of lower 